\title{
Role of oregano and Citrus species-based essential oil preparation for the control of coccidiosis in broiler chickens
}

Francisco Xavier Gordillo Jaramillo ${ }^{1 \dagger}$, Da-Hye Kim ${ }^{1 \dagger}$, Sang Hyeok Lee ${ }^{1}$, Sun-Kwan Kwon ${ }^{2}$, Rajesh Jha ${ }^{3}$ and Kyung-Woo Lee ${ }^{1 *}$ (i)

\begin{abstract}
Background: Due to presence of drug-resistant Eimeria strains and raised public health safety concerns about drug residues in the meat, there is renewed interest in the search for natural alternatives to the coccidiosis control agents. This study was conducted to test the anticoccidial efficacy of oregano and Citrus spp.-based essential oils for broilers.

Methods: A total of 280 7-day-old broiler chicks were fed a control diet or diets with salinomycin or essential oils for up to $35 \mathrm{~d}$ of age. On d 14, half of the control groups and the treated groups were orally challenged with a coccidiosis vaccine at 25 times higher than the recommended vaccine dose. Control diet-fed chickens that were gavaged with phosphate-buffered saline were considered non-challenged control group.

Results: Eimeria challenge or dietary additives failed to affect growth performance during the 7 to $20 \mathrm{~d}$ growth period although essential oil-fed chickens exhibited the lowest body wight gain $(P=0.332)$ and the highest feed conversion ratio $(P=0.062)$. Oocysts in the litter were detected in the challenged control diet group and the challenged/essential oil-fed groups at 21 and $35 \mathrm{~d}$, respectively. Superoxide dismutase activity in the serum was elevated $(P=0.059)$ in the salinomycin-fed chickens compared to the challenged controls. Alpha-1-acid glycoprotein was decreased by $28.7 \%$ in the salinomycin-fed chickens but increased by $38.1 \%$ in the essential oil group compared with the challenged control group. Challenged control group exhibited a significantly higher cooking loss of the thigh meat, compared to the non-challenged control diet group, which was marginally mitigated by dietary supplementation with essential oils. Chickens fed essential oil-added diet had the highest branched-chain fatty acids contents in the cecum.

(Continued on next page)
\end{abstract}

\footnotetext{
* Correspondence: kyungwoolee@konkuk.ac.kr

${ }^{\dagger}$ Francisco Xavier Gordillo Jaramillo and Da-Hye Kim contributed equally to this work.

'Department of Animal Science and Technology, Konkuk University, 120 Neungdong-ro, Gwangjin-gu, Seoul 05029, Republic of Korea

Full list of author information is available at the end of the article
}

(C) The Author(s). 2021 Open Access This article is licensed under a Creative Commons Attribution 4.0 International License, which permits use, sharing, adaptation, distribution and reproduction in any medium or format, as long as you give appropriate credit to the original author(s) and the source, provide a link to the Creative Commons licence, and indicate if changes were made. The images or other third party material in this article are included in the article's Creative Commons licence, unless indicated otherwise in a credit line to the material. If material is not included in the article's Creative Commons licence and your intended use is not permitted by statutory regulation or exceeds the permitted use, you will need to obtain permission directly from the copyright holder. To view a copy of this licence, visit http://creativecommons.org/licenses/by/4.0/ The Creative Commons Public Domain Dedication waiver (http://creativecommons.org/publicdomain/zero/1.0/) applies to the data made available in this article, unless otherwise stated in a credit line to the data. 


\begin{abstract}
(Continued from previous page)
Conclusions: In conclusion, this study shows that oregano and Citrus-based essential oil preparation did not affect growth performance in broiler chickens challenged with the coccidiosis vaccine nor did Eimeria-specific duodenal lesion. However, dietary essential oil preparation lowered oocysts present in litter materials and altered branchedchain fatty acids in cecal digesta. Beneficial findings of the essential oil preparation on volatile fatty acids and oocysts output may warrant further research into assessing its effectiveness and its efficacy in pathogenic fieldisolate Eimeria spp.-induced coccidiosis disease model.
\end{abstract}

Keywords: Broiler chickens, Coccidiosis, Essential oils, Growth performance, Salinomycin

\section{Background}

Avian coccidiosis is a devastating enteric disease that causes considerable economic loss to the poultry industry worldwide, accounting for US $\$ 3$ billion annually. This loss is mainly due to prophylactic or therapeutic infeed medications and compromised health of the afflicted chickens [1]. Avian coccidiosis is caused by several species of Eimeria, which are infectious protozoa that penetrate and damage the epithelial cells of the intestinal tissue, resulting in inflammation and hemorrhage [2]. The intestinal damage decreases feed intake, retards growth, and suppresses humoral- and cell-mediated immune responses, all of which adversely affect the poultry industry [3]. Avian coccidiosis was typically controlled by anticoccidial drugs such as synthetic (chemical) and ionophoric feed additives [4]. However, the long-term use of anticoccidial agents has led to drug-resistant Eimeria strains and raised public health safety concerns about drug residues in the meat [5]. Thus, there is renewed interest in the search for natural alternatives to the coccidiosis control agents $[6,7]$ and others like effective vaccines [4, 5]. Essential oils, classified as phytogenics [8], are a mixture of aromatic substances from herbs and spices. They have been used as an alternative to in-feed antibiotics in monogastric animals due to their antimicrobial properties [9]. The inclusion of essential oils in broilers' diets stimulated growth, modulated host immunity, improved gut health, and increased meat quality [8]. Essential oils from Origanum vulgare contain thymol and carvacrol as dominant components and have been widely used in poultry feed due to their strong antimicrobial and anticoccidial activities [10]. Essential oils from Citrus species, including orange, lemon, and lime contain limonene, linalool, and rterpinene as dominant components and have been used as flavoring agents in the food and perfume industries [11]. The Citrus-derived essential oils have also been used as food supplements to inhibit growth of foodpoisoning pathogens [12] and as a feed additive for chickens [9]. Citrus-based essential oils also exhibit anthelminthic [13] and antiparasitic activities [14]. Essential oils from $O$. vulgare and Citrus species have anticoccidial activities, so the synergistic effects of their combined preparations may provide a natural solution to control avian coccidiosis [15]. Indeed, a blend of essential oils from $O$. vulgare and Citrus spp. exhibited anticoccidial activities by decreasing coccidia invasion and stimulating growth in lambs [16]. Thus, it was hypothesized that a blend of $O$. vulgare and Citrus spp.based essential oils may be an effective alternative to control avian coccidiosis. To test the hypothesis, we reproduced experimental avian coccidiosis with high doses of the coccidiosis vaccine (as demonstrated by [17, 18]). As far as we know, this study was the first to test the anticoccidial activities of a blend of $O$. vulgare and Citrus spp.-based essential oils in coccidiosis chicken disease model.

\section{Materials and methods}

Experimental design, animals, and diets

A total of 280 1-day-old male broiler chicks (Ross 308) were obtained from a local hatchery. Upon arrival, the chicks were individually weighed and randomly placed into 28 floor pens with fresh rice hulls as a bedding material $\left(10\right.$ chicks/pen, 5 chicks $\left./ \mathrm{m}^{2}\right)$ and provided a commercial pre-starter diet. The corn and soybean mealbased pre-starter diet was in a crumbled form and fed from 1 to $7 \mathrm{~d}$ of age. The pre-starter diet had $3025 \mathrm{kcal}$ metabolizable energy per $\mathrm{kg}$ of diet and $22 \%$ crude protein. Seventy additional chicks were housed separately in the floor pens and used to replace dead or culled chicks during the first week.

In a completely randomized design, the chicks (on $\mathrm{d}$ 8) weighing (on average) $191 \pm 0.4 \mathrm{~g} / \mathrm{bird}$ per pen were randomly assigned to one of the following diets: a nonsupplemented control diet or diets supplemented with salinomycin (SAL; $60 \mathrm{mg} / \mathrm{kg}$ of diet; Decoxan ${ }^{\circ}$, Korea THUMB VET, Jeonbuk, South Korea) or an essential oil (EO) preparation $(500 \mathrm{mg} / \mathrm{kg}$ of diet). Additives were thoroughly mixed in the basal feeds before use. The commercially available EO preparation has been marketed as the natural alternative to coccidiostats and is a blend of essential oils extracted from oregano (Origanum vulgare) and Citrus spp., as described earlier [16]. Dietary EO was added at the concentration of 500 $\mathrm{mg} / \mathrm{kg}$ of diet, of which inclusion level has been known 
to alleviate avian coccidiosis [10]. At d 14, half of the control group (challenged control; INFECT) and all of the treated groups were challenged with $25 \times$ the recommended dose $\left(5 \times 10^{4}\right.$ oocysts per bird $)$ of the live coccidiosis vaccine (Coccivac ${ }^{\circ}-\mathrm{D}$, Intervet/Merck Animal Health, Omaha, NE, USA). We selected the $25 \times$ manufacturer's recommended dose of the live coccidiosis vaccine in an attempt to induce mild to moderate coccidiosis without mortality [18]. In addition, the authors chose the challenge time point at $d 14$ posthatch so that the anticoccidial effect of the tested additives could be determined on d 20 onward by measuring various parameters such as Eimeria-specific gut lesions, oocyst output, and growth performance. Per the manufacturer's specification, the vaccine contains live oocysts of E. acervuline, E. mivati, E. maxima, E. tenella, $E$ necatrix, E. brunetti, E. hagani, and E. praecox. The remaining control group chicks were gavaged with phosphate-buffered saline (CON; i.e., the non-challenged control). Each treatment had seven replicates of 10 chicks each ( $n=70$ chicks/treatment). The experimental schedule is depicted in Fig. 1.

The chicken facility was initially set at $32^{\circ} \mathrm{C}$, but the temperature was gradually decreased to $25^{\circ} \mathrm{C}$ at week 3 and maintained at this temperature thereafter. The light cycle was one-hour of darkness per day. Corn and soybean meal-based starter and finisher diets (Table 1) were formulated. The starter diet was provided from $\mathrm{d} 8$ to 20 , after which the finisher diet was provided until the end of the experiment $(35 \mathrm{~d})$. The basal diets did not contain antibiotics or anticoccidials but included a nonstarch polysaccharide degrading enzyme (Hemicell ${ }^{\circ}$, Elanco, Greenfield, IN, USA), phytase enzyme (Quantum $^{\circ}$ Blue, ABVista, Wiltshire, UK), and alternative to antibiotics (Monolaurin, Silo S.P.A., Firenze, Italy).

\section{Sampling}

Feed intake and body weight per pen were measured at 8,20 , and $35 \mathrm{~d}$ post-hatch and used to calculate the body weight gain (BWG), feed intake and feed conversion ratio (FCR). Mortality was recorded daily and used to adjust the growth performance data. On d 20, one bird per pen was randomly selected and euthanized by carbon dioxide $\left(\mathrm{CO}_{2}\right)$ asphyxiation. Immediately after euthanasia, blood was collected in vacutainer tubes by heart puncture, serum was obtained by gentle centrifugation (at $200 \times g$ for $15 \mathrm{~min}$ ), and the samples were stored at $20^{\circ} \mathrm{C}$ until further use. Immediately after blood sampling, the small intestine and a pair of ceca were excised. A segment of the duodenum was processed for measurements of the Eimeria-specific lesion and secretory immunoglobulin A (sIgA). The ceca were kept on ice until preparation for measurements of the volatile fatty acids (VFA) (described below). On d 35, one bird per pen was randomly selected and euthanized as described above. Immediately after euthanasia, the breast and thigh meats were sampled for meat quality. Finally, to monitor oocyst counts in the litter, five $500 \mathrm{~g}$ subsamples from 5 different spots ( 3 subsamples around the nipples and 2 subsamples around the feeder) in each pen were sampled on $\mathrm{d} 21$ and 35.

\section{Gut lesion scores and oocyst counts in the litter}

On $6 \mathrm{~d}$ post coccidiosis vaccine challenge (d 20 posthatch), the lesion score was measured on the duodenum of the small intestine [18]. However, it should be noted that coccidiosis vaccine used in this study contained

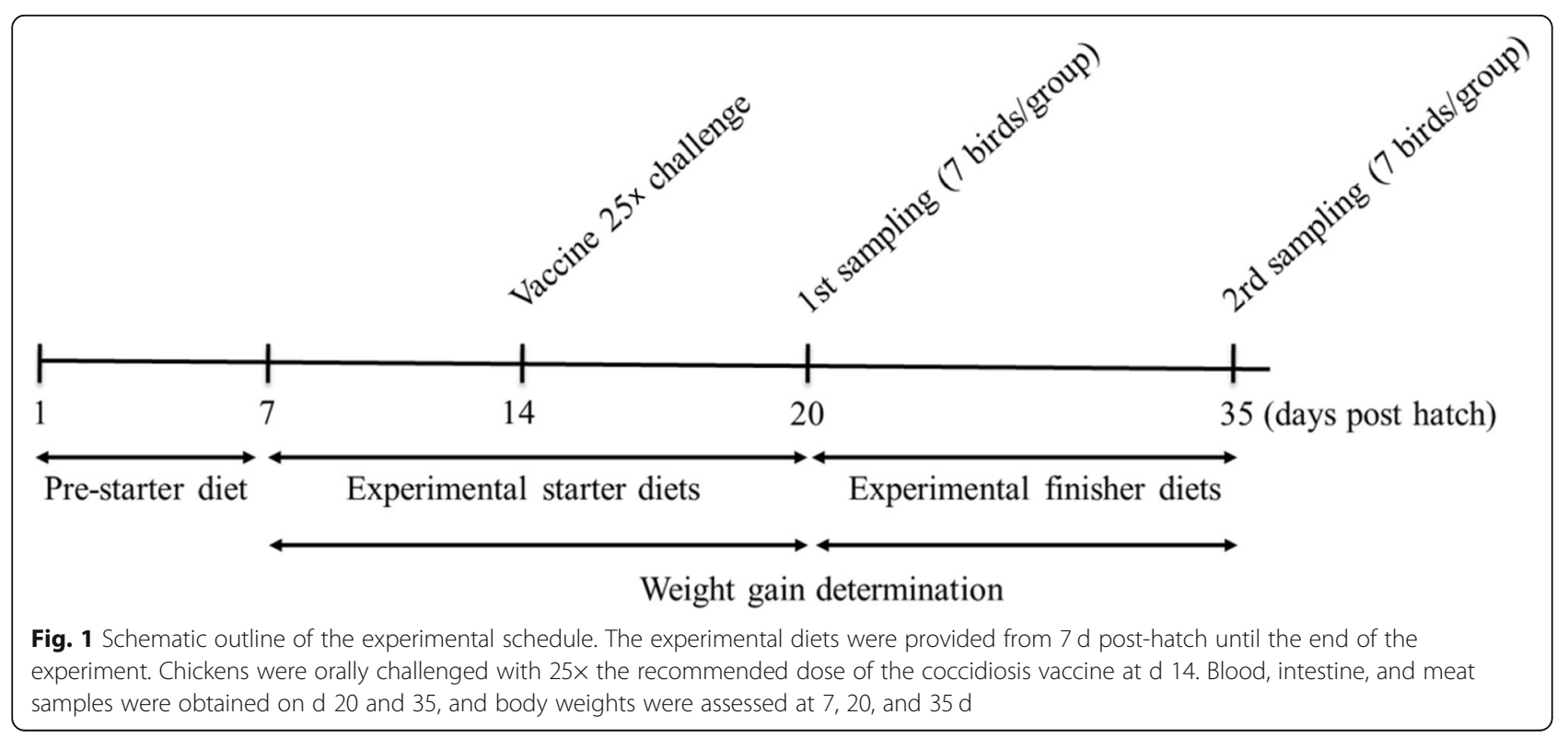


Table 1 Ingredients and nutrients composition of the starter and finisher diets

\begin{tabular}{|c|c|c|}
\hline Ingredients, g/100 g & Starter (8-20 d) & Finisher (21-35 d) \\
\hline Corn & 42.96 & 42.32 \\
\hline Wheat & 23.00 & 25.00 \\
\hline Soybean meal & 27.41 & 25.46 \\
\hline Corn gluten meal & 1.00 & 1.00 \\
\hline Beef tallow & 2.50 & 2.50 \\
\hline Lysine $\mathrm{HCl}$ & 0.11 & 0.72 \\
\hline $\mathrm{MHA}^{\mathrm{a}}$ (liquid methionine) & 0.44 & 0.45 \\
\hline L-Threonine & 0.09 & 0.08 \\
\hline Salt & 0.24 & 0.25 \\
\hline Limestone & 1.21 & 1.18 \\
\hline$D C P^{a}$ & 0.63 & 0.63 \\
\hline Vitamin/mineral premix ${ }^{\mathrm{b}}$ & 0.25 & 0.25 \\
\hline Choline chloride & 0.05 & 0.05 \\
\hline NSPase $e^{a}$ enzyme & 0.05 & 0.05 \\
\hline Phytase & 0.01 & 0.01 \\
\hline AGPa alternative & 0.05 & 0.05 \\
\hline Total & 100 & 100 \\
\hline \multicolumn{3}{|l|}{ Chemical composition } \\
\hline Metabolic energy ${ }^{c}, \mathrm{kcal} / \mathrm{kg}$ & 3150 & 3200 \\
\hline Dry matter ${ }^{d}, \%$ & 87.8 & 87.9 \\
\hline Crude protein ${ }^{c}, \%$ & 20.0 & 19.0 \\
\hline Crude fat ${ }^{d}, \%$ & 5.34 & 4.85 \\
\hline Crude ash ${ }^{d}, \%$ & 5.14 & 4.79 \\
\hline Calciumc, \% & 0.80 & 0.78 \\
\hline Total phosphorus'c, \% & 0.54 & 0.49 \\
\hline Available phosphorus`, \% & 0.35 & 0.35 \\
\hline Lysine $^{c}, \%$ & 1.33 & 1.22 \\
\hline Methionine ${ }^{c}, \%$ & 0.70 & 0.70 \\
\hline
\end{tabular}

${ }^{\text {a } M H A}$ Methionine hydroxy analogue, DCP Dicalcium phosphate, NSP Nonstarch polysaccharide, AGP Antibiotic growth promoter

${ }^{b}$ Vitamin and mineral premix provided the following nutrients per kg of diet: vitamin $A, 19,000$ IU; vitamin $D_{3}$, 5000 IU; vitamin $E_{1} 50$ mg; vitamin $K_{3}, 5.25 \mathrm{mg}$; thiamine, $3.50 \mathrm{mg}$; riboflavin, $14 \mathrm{mg}$; pyridoxine, $7 \mathrm{mg}$; cobalamin, $0.027 \mathrm{mg}$; niacin, $146.0 \mathrm{mg}$; biotin, $0.21 \mathrm{mg}$; folic acid, $1.75 \mathrm{mg}$; pantothenic acid, 22.85 $\mathrm{mg}, \mathrm{Fe}, 72 \mathrm{mg}$; Mn, 90 mg; Zn, 74 mg; I, $1.8 \mathrm{mg} ; \mathrm{Se}, 0.36 \mathrm{mg}$; Cu, $4.8 \mathrm{mg}$

'Calculated values

${ }^{\mathrm{d}}$ Analzyed values

multiple Eimeria species that can affect various segments of intestine ranging from duodenum to ceca. Duodenum was selectively examined for Emeria-induced lesions to evaluate the anticoccidial effects of the tested additives. The severity of the lesion was scored on a scale of 0 to 4 by three observers blind to the experimental treatments. Total oocysts present in the litter samples were isolated as described earlier [19] and oocysts isolated were counted using McMaster chamber. Oocysts were expressed as log oocyst counts per $g$ of litter.

\section{Secretory immunoglobulin A (slgA) contents in the gut mucosa}

On d 20, the duodenal segments were opened and washed to remove the digesta. The mucosa was collected by gently scraping the gut surface, homogenized with ice-cold sterilized saline, and centrifuged at $4000 \mathrm{r} / \mathrm{min}$ for $10 \mathrm{~min}$. The supernatant was stored at $-20{ }^{\circ} \mathrm{C}$ until further use. The secretory immunoglobulin A (sIgA) contents were measured via commercially available quantitative enzyme-linked immunosorbent assay (ELIS A) kits (Bethyl Laboratories, Montgomery, TX, USA) according to the manufacturer's recommendations. The sIgA contents are expressed per gram of protein. The protein content of the supernatant was measured by a commercial BCA Assay kit (Merck, Darmstadt, Germany).

\section{Volatile fatty acids}

Approximately $1 \mathrm{~g}$ of cecal digesta was added to $9 \mathrm{~mL}$ of cold distilled water and homogenized on an UltraTurrax (Digital Ultra-Turrax T25, IKA, Staufen, Germany). The mixture was combined with $0.05 \%$ of saturated mercuric chloride $\left(\mathrm{HgCl}_{2}\right), 1 \mathrm{~mL}$ of $25 \%$ phosphoric acid $\left(\mathrm{H}_{3} \mathrm{PO}_{4}\right)$, and $0.2 \mathrm{~mL}$ of $2 \%$ pivalic acid (as an internal standard) and centrifuged at $1000 \times g$ at $4{ }^{\circ} \mathrm{C}$ for $20 \mathrm{~min}$. The supernatant $(1.5 \mathrm{~mL})$ was collected and stored at $-20{ }^{\circ} \mathrm{C}$ until analysis. The concentrations of VFA were measured by gas chromatography (6890 Series GC System, HP, Palo Alto, CA, USA) as described by Kim et al. [20].

\section{Serum parameters}

The serum samples were analyzed for nitric oxide by using the Griess reagent (Sigma, St. Louis, MO, USA), glutathione by using the QuantiChorm antioxidant Assay Kit (BioAssay Systems, Hayward, CA, USA), superoxide dismutase (SOD) by using the SOD determination kit (Sigma, St. Louis, MO, USA), and alpha-1acid glycoprotein by using the chicken alpha-1-acid Glycoprotein Assay Kit (Life Diagnostics Inc., West Chester, PA, USA). All assays were conducted per the manufacturer's guidelines.

\section{Meat quality}

The breast and thigh muscles were evaluated for meat quality parameters (cooking loss, $\mathrm{pH}$, and color $24 \mathrm{~h}$ postmortem). To measure the cooking loss, fresh meats were placed in individual vacuum-sealed plastic bags, immersed in a water bath at $80^{\circ} \mathrm{C}$ for $30 \mathrm{~min}$, and cooled in running tap water (on ice) for $20 \mathrm{~min}$. The residual moisture from each sample was absorbed with tissue/filter paper. The cooking loss was calculated as the difference between the uncooked and cooked weights. The $\mathrm{pH}$ values were measured at three locations using a 
portable pH meter (Testo 205, AG Germany). The color of the fresh meats, including the lightness $\left(\mathrm{L}^{*}\right)$, redness $\left(a^{*}\right)$, and yellowness $\left(b^{*}\right)$ values, was measured using a reflectance colorimeter (CM-2600d/2500d, Minolta, Japan). Color was measured in triplicate on the boneside surface of each sample, and the colorimeter was calibrated with a standard white ceramic tile.

\section{Statistical analysis}

All of the data were analyzed by one-way analysis of variance using the general linear model procedure in SAS V9.3 (SAS Institute Inc., Cary, NC, USA). If the Ftests for treatment effects were significant, the differences between treatment means were tested by Duncan's multiple range test. The pen was considered an experimental unit. The significance level was pre-set at $P<$ 0.05 , and tendency was declared at $P<0.10$.

\section{Results}

There were no differences $(P>0.05)$ in BWG between the CONT and INFECT groups at any age, though BWG in the former was $4.80 \%$ higher, on average, during $\mathrm{d} 7$ to 20 (Table 2). The addition of SAL to the broilers' starter diet (7 to $20 \mathrm{~d}$ ) tended to increase BWG by $7.0 \%$ compared to the INFECT group. On the other hand, dietary EO did not affect BWG. None of treatments affected feed intakes. The FCR was highest $(P=$ 0.062 ) in the EO group, followed by the INFECT group, and was lowest in the CON and SAL groups. Both BWG and FCR during the finisher (21 to $35 \mathrm{~d}$ ) and whole grow-out ( 7 to $35 \mathrm{~d}$ ) periods were similar to the trends

Table 2 Effects of the dietary essential oil preparation on the growth performance in coccidiosis vaccine-challenged broiler chickens $^{a}$

\begin{tabular}{|c|c|c|c|c|c|c|}
\hline \multirow[t]{2}{*}{ Item } & \multicolumn{4}{|c|}{ Treatments $^{\mathrm{b}}$} & \multirow[t]{2}{*}{ SEM } & \multirow[t]{2}{*}{$P$-value } \\
\hline & CON & INFECT & SAL & EO & & \\
\hline \multicolumn{7}{|l|}{7 to $20 \mathrm{~d}$} \\
\hline BWG, g/bird & 678.7 & 646.1 & 677.8 & 633.9 & 19.916 & 0.332 \\
\hline Feed intake, g/bird & 1073 & 1024 & 1065 & 1064 & 22.350 & 0.629 \\
\hline Feed to gain, $\mathrm{g} / \mathrm{g}$ & 1.590 & 1.609 & 1.576 & 1.705 & 0.032 & 0.062 \\
\hline \multicolumn{7}{|l|}{21 to $35 d$} \\
\hline BWG, g/bird & 1493 & 1463 & 1490 & 1441 & 40.452 & 0.793 \\
\hline Feed intake, g/bird & 2462 & 2480 & 2325 & 2418 & 67.659 & 0.396 \\
\hline Feed to gain, $\mathrm{g} / \mathrm{g}$ & 1.641 & 1.698 & 1.566 & 1.701 & 0.037 & 0.054 \\
\hline \multicolumn{7}{|l|}{7 to $35 d$} \\
\hline BWG, g/bird & 2147 & 2100 & 2167 & 2088 & 50.764 & 0.678 \\
\hline Feed intake, g/bird & 3486 & 3471 & 3388 & 3479 & 74.620 & 0.797 \\
\hline Feed to gain, g/g 1 & 625 & 1.671 & 1.568 & 1.688 & 0.031 & 0.057 \\
\hline
\end{tabular}

${ }^{a}$ Values represent the mean of 7 replicates per treatment ( $n=7 /$ treatment) ${ }^{\mathrm{b}}$ CON Non-challenged naïve control, INFECT Challenged control, SAL Challenged/salinomycin-added diet, EO Challenged/essential oil-added diet, $B W G$ Body weight gain, SEM Standard error of the means observed for 7 to $20 \mathrm{~d}$. In short, chickens in the CON and SAL groups grew faster compared to the EO-added diet-fed chickens although there were no statistical differences between groups. Similarly, the FCR was higher in the INFECT and EO groups, but lower in the CON and SAL groups during the finisher phase $(P=0.054)$ and whole grow-out periods $(P=0.057)$.

Eimeria-specific lesions on the duodenal segments were not observed in the CON group but appeared in all chickens of the challenged groups (i.e., INFECT, SAL, and EO groups) at $6 \mathrm{~d}$ post-challenge. There were no differences in the gut lesions between the INFECT and challenged/treated groups (i.e., SAL and EO; Table 3). The INFECT control had the highest oocyst counts per $\mathrm{g}$ of litter $\left(\log _{10} 2.97\right)$, followed by the EO group ( $\log _{10}$ 2.87 ) on d 21 (Table 3). However, no oocysts were detected in the SAL-fed group. On d 35, oocysts were detected in all of the challenged groups, but there were significantly more oocysts $(P<0.05)$ in the INFECT group than in the EO-treated group. No oocysts were present in the litter samples of the CON group (at any age).

Eimeria challenge marginally reduced $(P=0.059)$ the SOD activity in the serum samples compared to the CON group (Table 4). However, supplementation of SAL or EO into the broilers' diets increased the Eimeriamediated decrease in serum SOD activity, being the former vs. the latter more effective. Eimeria challenge or dietary interventions did not affect the serum concentrations of glutathione or nitric oxide. The serum alpha-1acid glycoprotein level at d 20 was $160 \%$ higher in the INFECT group than in the CON group. The SAL-fed chickens had lower alpha-1-acid glycoprotein concentrations but the EO-fed chickens had higher concentrations (compared to the INFECT group). The sIgA contents in the duodenal mucosa were $2.4-3.5 \mathrm{ng} / \mathrm{g}$ of protein and did not differ $(P>0.05)$ between treatments (data not shown).

Table 3 Effects of the dietary essential oil preparation on the duodenal lesion scores and oocyst counts per gram of litter ${ }^{1}$

\begin{tabular}{|c|c|c|c|c|c|c|}
\hline \multirow[t]{2}{*}{ Item } & \multicolumn{4}{|c|}{ Treatment $^{2}$} & \multirow[t]{2}{*}{ SEM } & \multirow[t]{2}{*}{$P$-value } \\
\hline & $\overline{C O N}$ & INFECT & SAL & EO & & \\
\hline \multicolumn{7}{|l|}{$\mathrm{d} 20$} \\
\hline Lesion score & $0^{b}$ & $1.86^{\mathrm{a}}$ & $1.71^{\mathrm{a}}$ & $1.86^{\mathrm{a}}$ & 0.233 & $<0.001$ \\
\hline \multicolumn{7}{|c|}{ Oocysts, $\log _{10}$ oocysts/g litter } \\
\hline d 21 & $0^{\mathrm{b}}$ & $2.97^{\mathrm{a}}$ & $0^{\mathrm{b}}$ & $2.87^{\mathrm{a}}$ & 0.183 & $<0.001$ \\
\hline d 35 & $0^{c}$ & $3.15^{\mathrm{a}}$ & $2.82^{\mathrm{ab}}$ & $2.77^{\mathrm{b}}$ & 0.114 & $<0.001$ \\
\hline
\end{tabular}

${ }^{1}$ Values represent the mean of 7 replicates per treatment ( $n=7 /$ treatment) ${ }^{2}$ CON Non-challenged naïve control, INFECT Challenged control, SAL Challenged/salinomycin-added diet, EO Challenged/essential oil-added diet, SEM Standard error of the means

${ }^{a-c}$ Means with different superscripted letters differ significantly $(P<0.05)$ 
Table 4 Effects of the dietary essential oil preparation on the serum antioxidant and immunity markers in coccidiosis vaccinechallenged broiler chickens ${ }^{1}$

\begin{tabular}{|c|c|c|c|c|c|c|}
\hline \multirow[t]{2}{*}{ Item } & \multicolumn{4}{|c|}{ Treatment $^{2}$} & \multirow[t]{2}{*}{ SEM } & \multirow[t]{2}{*}{$P$-value } \\
\hline & CON & $\begin{array}{l}\text { INFE } \\
\text { CT }\end{array}$ & SAL & EO & & \\
\hline \multicolumn{7}{|l|}{ d 20} \\
\hline SOD activity, \% & 96.2 & 94.3 & 96.4 & 95.0 & 0.540 & 0.059 \\
\hline $\begin{array}{l}\text { Glutathione, } \mathrm{mol} / \mathrm{l} \\
\mathrm{L}\end{array}$ & 139.0 & 136.3 & 135.3 & 138.3 & 1.384 & 0.241 \\
\hline $\mathrm{a} 1-\mathrm{AGP}, \mu \mathrm{g} / \mathrm{mL}$ & $211.8^{b}$ & $551.1^{a b}$ & $392.7^{b}$ & $760.8^{a}$ & 101.09 & 0.026 \\
\hline $\begin{array}{l}\text { Nitric oxide, } \mu \mathrm{mol} / \\
\mathrm{L}\end{array}$ & 19.8 & 21.1 & 17.2 & 19.7 & 1.245 & 0.254 \\
\hline \multicolumn{7}{|c|}{$\begin{array}{l}{ }^{1} \text { Values represent the mean of } 7 \text { replicates per treatment }(n=7 / \text { treatment) } \\
{ }^{2} C O N \text { Non-challenged naïve control, INFECT Challenged control, SAL } \\
\text { Challenged/salinomycin-added diet, EO Challenged/essential oil-added diet, } \\
\text { SOD Superoxide dismutase, a1-AGP Alpha-1-acid glycoprotein, SEM Standard } \\
\text { error of the means } \\
{ }^{a-b} \text { Means with different superscripted letters differ significantly }(P<0.05)\end{array}$} \\
\hline
\end{tabular}

It was observed that acetate was the dominant VFA in the cecum, followed by butyrate and propionate (Table 5). Branched-chain fatty acid (BCFA) contents (i.e., isobutyrate, isovalerate, and valerate) were kept low in all treated groups and their concentrations were less than $0.8 \mu \mathrm{mol} / \mathrm{g}$ cecal contents. Although nonsignificant $(P=0.164)$, Eimeria challenge lowered the total VFA contents by $19 \%$ compared to the CON group. The EO group had highest contents $(P<0.05)$ of isobutyrate and BCFA in the cecum.

Eimeria challenge or dietary additives did not affect the meat yields and qualities of broiler chickens sampled at $35 \mathrm{~d}$ (Table 6). Eimeria challenge increased the cooking loss of the thigh meats compared to the $\mathrm{CON}$ group.

Table 5 Effects of the dietary essential oil preparation on the concentrations of cecal volatile fatty acids $(\mu \mathrm{mol} / \mathrm{g})$ on $\mathrm{d} 20$ in coccidiosis vaccine-challenged broiler chickens ${ }^{1}$

\begin{tabular}{llllllll}
\hline Item $^{1}$ & \multicolumn{2}{l}{ Treatment $^{\mathbf{2}}$} & \multicolumn{3}{l}{ SEM $^{\mathbf{3}}$} & $\begin{array}{l}\boldsymbol{P} \text { - } \\
\text { value }\end{array}$ \\
\cline { 2 - 5 } & CON & INFECT & SAL & EO & & \\
\hline Acetate & 44.3 & 36.4 & 39.1 & 42.6 & 4.190 & 0.560 \\
Propionate & 3.38 & 2.98 & 2.24 & 3.73 & 0.357 & 0.106 \\
Isobutyrate & $0.16^{\mathrm{ab}}$ & $0.15^{\mathrm{b}}$ & $0.09^{\mathrm{b}}$ & $0.24^{\mathrm{a}}$ & 0.027 & 0.021 \\
Butyrate & 16.5 & 12.5 & 14.8 & 17.6 & 2.620 & 0.590 \\
Isovalerate & 0.30 & 0.28 & 0.19 & 0.53 & 0.079 & 0.061 \\
Valerate & 0.62 & 0.61 & 0.62 & 0.79 & 0.117 & 0.693 \\
BCFAs & $1.12^{\mathrm{b}}$ & $1.02^{\mathrm{b}}$ & $0.72^{\mathrm{b}}$ & $1.81^{\mathrm{a}}$ & 0.161 & 0.003 \\
Total VFAs & 65.3 & 52.9 & 57.0 & 65.5 & 8.784 & 0.164
\end{tabular}

${ }^{1}$ Values represent the mean of 7 replicates per treatment $(n=7 /$ treatment) ${ }^{2}$ CON Non-challenged naïve control, INFECT Challenged control, SAL Challenged/salinomycin-added diet, EO Challenged/essential oil-added diet, $B C F A s$ Branched-chain fatty acids (isobutyrate + valerate + isovalerate), Total VFAs Total volatile fatty acids (acetate + propionate + butyrate + isobutyrate + valerate + isovalerate), SEM Standard error of the means

${ }^{a-b}$ Means with different superscripted letters differ significantly $(P<0.05)$
However, dietary supplementation with SAL or EO did not counteract the challenge-induced increase in cooking loss, although the latter partially decreased it.

\section{Discussion}

Avian coccidiosis is a devastating enteric disease caused by several species of Eimeria that results in huge economic losses. Several anticoccidial agents, including ionophores, have been added to poultry diets to control coccidiosis, but there are growing concerns over the emergence of drug-resistant oocysts and drug residues in the meats. Essential oil-based preparations have been marketed as an alternative natural anticoccidial, as they have multiple biological properties that directly inhibit the Eimeria spp. They also upregulate the host immune response, improve the antioxidant capacity, and exhibit antimicrobial activity upon ingestion [8]. We used the $20 \times$ of the manufacture's recommended dose of the vaccine via gavage [17] and this reflects the farm conditions of Eimeria infection, which are typically infested with multiple Eimeria oocysts. The anticoccidial efficacy of $O$. vulgare and Citrus spp.-based essential oils [16] were determined in the vaccine-induced coccidiosis model.

In this study, inoculation with high doses of live coccidiosis vaccine at $14 \mathrm{~d}$ post-hatch did not impair growth performance of the chickens although BWG of the INFE CT group was reduced by an average of $4.8 \%$ during the phase compared to that of the CON group. During the

Table 6 Effects of the dietary essential oil preparation on the yields and quality of breast and thigh meats from coccidiosis vaccine-challenged broiler chickens

\begin{tabular}{lllllll}
\hline Item & \multicolumn{3}{l}{ Treatment $^{2}$} & & SEM & $\begin{array}{l}\boldsymbol{P} \text { - } \\
\text { value }\end{array}$ \\
\cline { 2 - 5 } & CON & INFECT & SAL & EO & & \\
\hline Breast meat & & & & & & \\
Meat, g/100 BW & 8.40 & 8.36 & 8.06 & 8.28 & 0.226 & 0.735 \\
Cooking loss, \% & 17.6 & 17.3 & 16.0 & 17.3 & 0.633 & 0.385 \\
CIE L* (lightness) & 54.2 & 56.0 & 56.1 & 54.7 & 1.366 & 0.713 \\
CIE a* (redness) & 0.117 & -0.344 & -0.914 & -0.297 & 0.354 & 0.258 \\
CIE b* (yellowness) & 10.9 & 10.4 & 10.2 & 10.3 & 0.600 & 0.836 \\
pH & 5.65 & 5.72 & 5.63 & 5.62 & 0.031 & 0.198 \\
Leg meat & & & & & & \\
Meat, g/100 BW & 6.43 & 6.60 & 6.37 & 6.44 & 0.086 & 0.282 \\
Cooking loss, \% & $20.6^{b}$ & $24.8^{\mathrm{a}}$ & $25.2^{\mathrm{a}}$ & $23.5^{\mathrm{ab}}$ & 1.041 & 0.026 \\
CIE L* & 54.4 & 53.4 & 55.8 & 54.6 & 1.139 & 0.531 \\
CIE a* & 2.13 & 3.05 & 1.56 & 2.31 & 0.410 & 0.108 \\
CIE b* & 7.61 & 8.87 & 8.85 & 9.25 & 0.586 & 0.241 \\
pH & 6.23 & 6.17 & 6.23 & 6.14 & 0.062 & 0.653 \\
\hline
\end{tabular}

${ }^{1}$ Values represent the mean of 7 replicates per treatment ( $n=7 /$ treatment) ${ }^{2}$ CON Non-challenged naïve control, INFECT Challenged control, SAL Challenged/salinomycin-added diet, EO Challenged/essential oil-added diet, $B W$ Body weight, SEM Standard error of the means

${ }^{a-b}$ Means with different superscripted letters differ significantly $(P<0.05)$ 
finisher phase, BWG in the INFECT vs. the CON group was $2.2 \%$ lower (on average), indicating recovery from the coccidiosis challenge with age. The difference in the FCR of the CON vs. the INFECT groups tended to be wider $(1.2 \%$ to $3.5 \%)$ during the starter and finisher phases. Thus, the impact of the coccidiosis vaccine challenge on production performance persisted throughout the study period but was minimal. The lack of a challenge effect on performance may be related to the composition of the basal diet used in this study containing exogenous enzymes and probiotics or timing of challenge. This was intended to reflect the field situation, as commercial diets contain several feed additives, such as exogenous enzymes (e.g., phytase, NSPase, protease, or lipase), amino acids, vitamins, minerals, and mediumchain fatty acids. Dersjant-Li et al. [21] reported that a combination of exogenous enzymes and Bacillus spp.based probiotics reduced the gut damage and performance loss caused by coccidial challenge. Dietary monolaurate, marketed as an alternative to antibiotics, played an important role in stimulating growth and improving meat quality when included in the diets of broiler chickens [22]. Finally, phytase supplementation to broiler chicken diets was equally effective at improving the growth performance with or without Eimeria acervuline challenge [23]. Thus, the negative performance effects of $25 \times$ the recommended dose of the coccidial vaccine [24] appear to be minimal in this study. The chickens fed with a diet containing anticoccidial SAL performed equal to the CON group, but EO-fed chickens performed lowest (i.e., FCR) in all treatment groups. These results indicate that dietary anticoccidial vs. natural alternatives is more effective at controlling avian coccidiosis. At this stage, it is not clear why dietary EO did not affect BWG of chickens following Eimeria vaccine challenge. Further studies are required to investigate whether the dietary EO mitigate avian coccidiosis induced by field-type Eimeria spp. or higher doses of the coccidiosis vaccine.

Chick's exposure to Eimeria spp. impairs the host antioxidant defense mechanisms via Eimeria-induced gut damage that triggers intestinal oxidative stress - this is the area of action for in-feed antioxidants as natural anticoccidial agents [6]. Indeed, Gadde et al. [8] observed beneficial effects of EO preparations due to their wellknown antioxidant properties. In this study, the Eimeria vaccine challenge induced oxidative stress as evidenced by decreased SOD activity in the serum, and the Eimeria-induced oxidative stress was partially mitigated by dietary SAL. Dietary EO did not improve the antioxidant capacity of the broiler chickens but tended to increase the SOD activity compared to that of the INFECT group. Idris et al. [25] found that EO with in vitro and in vivo antioxidant activities exhibited variable results for avian coccidiosis. Alpha-1-acid glycoprotein is a moderate acute-phase protein that is secreted from the hepatocytes in response to inflammation or infection. Increased levels of the acute-phase proteins, including alpha-1-acid glycoprotein, in the blood serve to restore the disturbed homeostatic conditions during healing [26]. However, this process negatively affects production performance, as elevated acute-phase protein levels require energy expenditure [27]. In line with the SOD activity patterns, the serum concentrations of alpha-1-acid glycoprotein were elevated by the Eimeria vaccine challenge but were mitigated by dietary SAL. The latter finding coincides with the increased antioxidant capacity of SAL and may explain the increased BWG in this group compared to the INFECT group. Interestingly, the dietary EO preparations further aggravated the Eimeria-induced increase in alpha-1-acid glycoproteins. How the dietary EO elevated the vaccine-challenged increase in acute-phase proteins is unclear and requires further investigation.

Giannenas et al. [28] reported that the coliform in the cecal contents of broiler chickens was altered by coccidiosis challenge. Macdonald et al. [29] noted that the amount of Enterobacteriaceae in the cecum increased, while the abundances of Bacillales and Lactobacillales decreased in chicks inoculated with Eimeria tenella (compared to a non-challenged control). Indeed, Eimeria infection marginally reduced the total VFA by $19 \%$ compared to that of the CON group; this is consistent with the observations of Leung et al. [30]. However, the addition of SAL or the EO preparation into the diets following Eimeria vaccine challenge did not affect the VFA concentrations in the cecum (though dietary EO preparation increased the BCFA contents). It is known that increased concentrations of VFA in the gut digesta can be considered beneficial, as they inhibit pathogenic bacteria invasion and aid enterocyte homeostasis [31]. On the other hand, excessive accumulation of BCFA contents noted in this study might indicate the abnormal scenario of fermentation by gut microbiota on the non-absorbed amino acids or proteins reaching the cecum. It is of interest to see that the increased concentration of BCFA contents in the EO group (see Table 5) is associated with highest FCR during $\mathrm{d} 7$ to 20 (see Table 2). Thus, it might be likely that the increase in BCFA contents in the EO group is in part related to EO-mediated change in gut microbiota or protein digestion, especially at early days. However, as the portion of BCFA contents in total VFA is kept minimal, their contribution on gut health needs to be clarified.

In this study, the breast and thigh muscle meat qualities were analyzed on the 21st day post-Eimeria vaccine challenge (i.e., $35 \mathrm{~d}$ of age) to investigate if early exposure to Eimeria affects meat qualities. Eimeria challenge 
significantly increased the cooking loss of thigh meat compared to that of the CON group. In contrast to our results, Chodova et al. [32] reported that subclinical $E$. tenella infection did not affect the meat color and cooking loss of broiler chicken breast meat. Interestingly, the dietary EO preparation tended to lower the cooking loss of thigh meat compared to that of the INFECT group. Tauer et al. [33] reported that dietary oregano essential oil did not affect the $\mathrm{pH}$ of the breast meat but increased the meat colors when the broiler chickens were exposed to a coccidiosis disease challenge. The results of our study, supported by earlier work [32, 33], suggest that the meat quality of broiler chickens challenged by Eimeria warrants further investigation.

\section{Conclusions}

In conclusion, dietary SAL vs. EO performed better in broiler chickens following coccidiosis vaccine challenge. Dietary EO preparation lowered the amounts of oocysts present in the litter and increased the VFA concentration in the cecal digesta. Further studies are required to evaluate the effect of EO preparations on gut health including gut barrier parameter and gut microbiota profile in experimental coccidiosis induced by pathogenic fieldtype Eimeria spp.

\section{Abbreviations \\ BCFA: Branched-chain fatty acid; BWG: Body weight gain; ELISA: Enzyme- linked immunosorbent assay; EO: Essential oil; FCR: Feed conversion ratio; SAL: Salinomycin; slgA: Secretory immunoglobulin A; SOD: Superoxide dismutase; VFA: Volatile fatty acids}

\section{Acknowledgments}

The authors acknowledge the graduate students in the Laboratory of Poultry Science at Konkuk University, South Korea, who helped with bird care and data collection.

\section{Authors' contributions}

RJ, SKK, and KWL: designed the experiment; SHL: purchased reagents; FXG DHK, and SHL: conducted the experiment; DHK: conducted statistical analysis; RJ and KWL: wrote and revised the manuscript. All authors have contributed, read, and approved the final manuscript.

\section{Funding}

This paper was supported by Konkuk University in 2020.

\section{Availability of data and materials}

The raw data for the current study are available from the corresponding author on reasonable request.

\section{Ethics approval and consent to participate}

These studies were approved by the Institutional Animal Care and Use Committee of Konkuk University (Gwangjin-gu, Seoul, Republic of Korea; KU15186).

\section{Consent for publication}

Not applicable.

\section{Competing interests}

The authors declare that they have no competing interests.

\section{Author details}

'Department of Animal Science and Technology, Konkuk University, 120 Neungdong-ro, Gwangjin-gu, Seoul 05029, Republic of Korea. ${ }^{2}$ Harim Bio Research Center, Jeilfeed Co., LTD, 136 Techno2-ro, Yuseong-gu, Deajeon-si 34025, Republic of Korea. ${ }^{3}$ Department of Human Nutrition, Food and Animal Sciences, College of Tropical Agricultural and Human Resources, University of Hawaii at Manoa, Honolulu, HI 96822, USA.

Received: 13 October 2020 Accepted: 7 February 2021

Published online: 06 April 2021

\section{References}

1. Lee KW, Lillehoj HS, Jang SI, Li G, Lee SH, Lillehoj EP, et al. Effect of Bacillusbased direct-fed microbials on Eimeria maxima infection in broiler chickens. Comp Immunol Microbiol Infect Dis. 2010;33:e105-10.

2. Lillehoj HS, Trout JM. Avian gut-associated lymphoid tissues and intestinal immune responses to Eimeria parasites. Clin Microbiol Rev. 1996;9:349-60.

3. Lillehoj HS, Lillehoj EP. Avian coccidiosis. A review of acquired intestinal immunity and vaccination strategies. Avian Dis. 2000;44(2):408-25.

4. Shirley MW, Lillehoj HS. The long view: a selective review of 40 years of coccidiosis research. Avian Pathol. 2012;41:111-21.

5. Peek HW, Landman WJM. Coccidiosis in poultry: anticoccidial products, vaccines and other prevention strategies. Vet Q. 2011;31:143-61.

6. Bozkurt M, Selek N, Küçükyilmaz K, Eren H, Güven E, Çatli AU, et al. Effects of dietary supplementation with a herbal extract on the performance of broilers infected with a mixture of Eimeria species. Br Poult Sci. 2012;53:32532.

7. Adhikari P, Kiess A, Adhikari R, Jha R. An approach to alternative strategies to control avian coccidiosis and necrotic enteritis. J Appl Poult Res. 2020;29: 515-34.

8. Gadde U, Kim WH, Oh ST, Lillehoj HS. Alternatives to antibiotics for maximizing growth performance and feed efficiency in poultry: a review. Anim Health Res Rev. 2017;18:26-45.

9. Zhai H, Liu H, Wang S, Wu J, Kluenter AM. Potential of essential oils for poultry and pigs. Anim Nutr. 2018:4:179-86.

10. Mohiti-Asli M, Ghanaatparast-Rashti M. Dietary oregano essential oil alleviates experimentally induced coccidiosis in broilers. Prev Vet Med. 2015; 120:195-202.

11. González-Mas MC, Rambla JL, López-Gresa MP, Amparo Blázquez M, Granell A. Volatile compounds in Citrus essential oils: a comprehensive review. Front Plant Sci. 2019;10:12

12. Fisher K, Phillips CA. The effect of lemon, orange and bergamot essential oils and their components on the survival of Campylobacter jejuni, Escherichia coli 0157, Listeria monocytogenes, Bacillus cereus and Staphylococcus aureus in vitro and in food systems. J Appl Microbiol. 2006; 101:1232-40.

13. Gaínza YA, Domingues LF, Perez OP, Rabelo MD, López ER, Chagas AC de S. Anthelmintic activity in vitro of Citrus sinensis and Melaleuca quinquenervia essential oil from Cuba on Haemonchus contortus. Ind Crop Prod. 2015;76: 647-52.

14. Favela-Hernández JMJ, González-Santiago O, Ramírez-Cabrera MA, EsquivelFerriño PC, Camacho-Corona MDR. Chemistry and pharmacology of Citrus sinensis. Molecules. 2016;21:247.

15. Pop LM, Varga E, Coroian M, Nedisan ME, Mircean V, Dumitrache MO, et al. Efficacy of a commercial herbal formula in chicken experimental coccidiosis. Parasit Vectors. 2019;12:343.

16. Dudko P, Junkuszew A, Bojar W, Milerski M, Szczepaniak K, Le Scouarnec J, et al. Effect of dietary supplementation with preparation comprising the blend of essential oil from Origanum vulgare (Lamiaceae) and Citrus spp. (Citraceae) on coccidia invasion and lamb growth. Ital J Anim Sci. 2018;17: 57-65.

17. Mathis GF, Newman LJ, Fitz-Coy S, Lumpkins B, Charette R, Fuller L. Comparison of breeder/layer coccidiosis vaccines: part 1 -precocity and pathogenicity. J Appl Poult Res. 2018;27:33-7.

18. Lee JW, Kim DH, Kim YB, Jeong SB, Oh ST, Cho SY, et al. Dietary encapsulated essential oils improve production performance of coccidiosisvaccine-challenged broiler chickens. Animals. 2020;10:481

19. Lee KW, Lillehoj HS, Jang SI, Pagès M, Bautista DA, Pope CR, et al. Effects of in ovo vaccination and anticoccidials on the distribution of Eimeria spp. in poultry litter and serum antibody titers against coccidia in broiler chickens raised on the used litters. Res Vet Sci. 2012;93:177-82. 
20. Kim DH, Han SM, Keum MC, Lee $S$, An BK, Lee SR, et al. Evaluation of bee venom as a novel feed additive in fast-growing broilers. Br Poult Sci. 2018; 59:435-42.

21. Dersjant-Li Y, Gibbs K, Awati A, Klasing KC. The effects of enzymes and direct fed microbial combination on performance and immune response of broilers under a coccidia challenge. J Appl Anim Nutr. 2016;4:e6.

22. Fortuoso BF, dos Reis JH, Gebert RR, Barreta M, Griss LG, Casagrande RA, et al. Glycerol monolaurate in the diet of broiler chickens replacing conventional antimicrobials: impact on health, performance and meat quality. Microb Pathog. 2019;129:161-7.

23. Watson BC, Matthews JO, Southern LL, Shelton JL. The interactive effects of Eimeria acervulina infection and phytase for broiler chicks. Poult Sci. 2005;84: 910-3.

24. Zhang Q, Chen X, Eicher SD, Ajuwon KM, Applegate TJ. Effect of threonine deficiency on intestinal integrity and immune response to feed withdrawal combined with coccidial vaccine challenge in broiler chicks. Br J Nutr. 2016; 116:2030-43.

25. Idris M, Abbas RZ, Masood S, Rehman T, Farooq U, Babar W, et al. The potential of antioxidant rich essential oils against avian coccidiosis. Worlds Poult Sci J. 2017;73:89-104.

26. Lee KW, Lee KN, Lillehoj HS, Park JH. Serum concentration of acute phase proteins and cytokines in vaccinated pigs challenged with foot-and-mouth disease virus serotype O. Rev Bras Zootec. 2019;48:e20180190.

27. O'Reilly EL, Bailey RA, Eckersall PD. A comparative study of acute-phase protein concentrations in historical and modern broiler breeding lines. Poult Sci. 2018;97(11):3847-53.

28. Giannenas I, Tsalie E, Triantafillou E, Hessenberger S, Teichmann K, Mohnl M, et al. Assessment of probiotics supplementation via feed or water on the growth performance, intestinal morphology and microflora of chickens after experimental infection with Eimeria acervulina, Eimeria maxima and Eimeria tenella. Avian Pathol. 2014;43:209-16.

29. Macdonald SE, Nolan MJ, Harman K, Boulton K, Hume DA, Tomley FM, et al. Effects of Eimeria tenella infection on chicken caecal microbiome diversity, exploring variation associated with severity of pathology. PLoS One. 2017; 12:e0184890.

30. Leung H, Yitbarek A, Snyder R, Patterson R, Barta JR, Karrow N, et al. Responses of broiler chickens to Eimeria challenge when fed a nucleotiderich yeast extract. Poult Sci. 2019;98:1622-33.

31. Meimandipour A, Shuhaimi M, Soleimani AF, Azhar K, Hair-Bejo M, Kabeir $\mathrm{BM}$, et al. Selected microbial groups and short-chain fatty acids profile in a simulated chicken cecum supplemented with two strains of Lactobacillus. Poult Sci. 2010;89:470-6.

32. Chodová D, Tůmová E, Sládková K, Langrová I, Jankovská I, Vadlejch J, et al. Effects of subclinical Eimeria tenella infection on Pectoralis major muscle in broiler chickens. Ital J Anim Sci. 2018;17:18-21.

33. Tauer SK, Holt JP, Underwood KR, Levesque CL, Thaler RC. Performance, histology, and meat quality of coccidiosis-challenged broilers fed essential oils. Meat Muscle Biol. 2019;3:13-21.

Ready to submit your research? Choose BMC and benefit from:

- fast, convenient online submission

- thorough peer review by experienced researchers in your field

- rapid publication on acceptance

- support for research data, including large and complex data types

- gold Open Access which fosters wider collaboration and increased citations

- maximum visibility for your research: over $100 \mathrm{M}$ website views per year

At BMC, research is always in progress.

Learn more biomedcentral.com/submissions 